\title{
Divergence and convergence in nutrition science
}

Citation for published version (APA):

Penders, B., Spruit, S. L., Sikkema, J., Maat, J., \& Schuurbiers, D. (2015). Divergence and convergence in nutrition science. Trends in Food Science \& Technology, 45(2), 245-250.

https://doi.org/10.1016/j.tifs.2015.07.008

Document status and date:

Published: 01/01/2015

DOI:

10.1016/j.tifs.2015.07.008

Document Version:

Publisher's PDF, also known as Version of record

Document license:

Taverne

Please check the document version of this publication:

- A submitted manuscript is the version of the article upon submission and before peer-review. There can be important differences between the submitted version and the official published version of record.

People interested in the research are advised to contact the author for the final version of the publication, or visit the DOI to the publisher's website.

- The final author version and the galley proof are versions of the publication after peer review.

- The final published version features the final layout of the paper including the volume, issue and page numbers.

Link to publication

\footnotetext{
General rights rights.

- You may freely distribute the URL identifying the publication in the public portal. please follow below link for the End User Agreement:

www.umlib.nl/taverne-license

Take down policy

If you believe that this document breaches copyright please contact us at:

repository@maastrichtuniversity.nl

providing details and we will investigate your claim.
}

Copyright and moral rights for the publications made accessible in the public portal are retained by the authors and/or other copyright owners and it is a condition of accessing publications that users recognise and abide by the legal requirements associated with these

- Users may download and print one copy of any publication from the public portal for the purpose of private study or research.

- You may not further distribute the material or use it for any profit-making activity or commercial gain

If the publication is distributed under the terms of Article $25 \mathrm{fa}$ of the Dutch Copyright Act, indicated by the "Taverne" license above, 
Review

\title{
Divergence and convergence in nutrition science
}

\author{
Bart Penders ${ }^{\text {a, }}$, Shannon L. Spruit ${ }^{\text {b }}$, Jan Sikkema ${ }^{c}$, Jan Maat ${ }^{\mathrm{d}}$, Daan Schuurbiers ${ }^{\text {e }}$ \\ ${ }^{a}$ Health, Ethics \& Society, School of Public Health \& Primary Care (CAPHRI), Maastricht University, PO Box 616, 6200MD, Maastricht, The Netherlands \\ ${ }^{\mathrm{b}}$ Values, Technology \& Innovation, School of Technology, Business and Management, Delft University of Technology, PO Box 5015, 2600GA, Delft, The \\ Netherlands \\ ${ }^{c}$ Center for Development and Innovation, University Medical Center Groningen, PO Box 30001, 9700RB Groningen, The Netherlands \\ ${ }^{\mathrm{d}}$ Top Institute Food and Nutrition (TIFN), PO Box 557, 6700 AN Wageningen, The Netherlands \\ e Responsible Innovation Collective, Molenveldlaan 194, 6523 RP Nijmegen, The Netherlands
}

\section{A R T I C L E I N F O}

\section{Article history:}

Received 7 October 2014

Received in revised form

3 June 2015

Accepted 14 July 2015

Available online 20 July 2015

\section{Keywords:}

Nutrigenomics

Divergence

Convergence

Research policy

Collaboration

Research cultures

\begin{abstract}
A B S T R A C T
Nutrigenomics diverged from mainstream nutrition science, ideologically, instrumentally and culturally, due to the establishment of a protective niche. That protection is fading. This article chronicles a case in which convergence between nutrigenomics and nutrition science is pursued. Here we report the opportunities and hurdles that researchers within two large Dutch research consortia encountered when trying to engineer collaboration. The most salient hurdles are the complexity of and unfamiliarity with nutrigenomics, unclear and unshared notions of relevance; difficulties in organising data exchange; and the existence of two research cultures. Overcoming these technical and social hurdles will require the development of a shared 'future' for the relationship between nutrigenomics and nutrition science.
\end{abstract}

(C) 2015 Elsevier Ltd. All rights reserved.

\section{Introduction}

Well over a decade ago, nutrigenomics diverged from mainstream nutritional science as a specific methodological and conceptual approach (Müller \& Kersten, 2003). Over the course of this decade, the identity of nutrigenomics as an independent field of research was firmly established- sometimes in opposition to 'nutrition science'. Key ingredients to nutrigenomics are a focus on molecular mechanisms, the search for mechanistic understandings of nutrient metabolism and a focus on individuality over assumptions of population uniformity. Nutrigenomics researchers have been very successful, academically, as knowledge producers, and have been producing a steady stream of high impact publications in both the nutrition field and high impact journals in genetics and medicine. Additionally, they have been effective in securing funding for specific nutrigenomic research projects and collaborations around the globe. The acquisition of this funding has been accompanied by a rhetoric actively enlarging the differences, and solidifying the boundary, between 'traditional' nutrition science

\footnotetext{
* Corresponding author.

E-mail address: b.penders@maastrichtuniversity.nl (B. Penders).
}

and the 'new' science of nutrigenomics. This rhetoric envisioned a specific future in which diet and nutrition would be specifically adapted to individual differences. Increasing stratification was suggested to be an improvement over dominant one-size-fits-all approaches, paradigmatic to existing nutrition science (Müller \& Kersten, 2003).

This rhetoric of differentiation has resulted in a protective niche for nutrigenomics (Penders \& Goven, 2010; Webster, 2007) securing some degree of independence from nutrition science writ large. Nutrigenomics developed into a recognised field that pursued its own questions and developed its own infrastructure, albeit at a relatively high proximity to nutrition science. To date, nutrigenomics has grown into an academic specialisation with its own consortia, professors, journals, and an institutional foundation for training new nutrigenomicists.

In recent years however, the protective boundaries that have separated nutrigenomics and nutrition science have begun to crumble. The large amounts of funding specifically earmarked for nutrigenomics are diminishing across the globe The question for the coming years is therefore how nutrigenomics will relate to nutrition science, now that its protective niche is fading. Further divergence and renewed convergence are possible dynamics each worth studying in detail. Local and regional variations 
notwithstanding, shifting degrees of collaboration and synthesis between nutrigenomics and nutrition science will undoubtedly redefine the ideological and methodological focus of nutrition science. As an example of the dynamics that ensue when the protective niche of nutrigenomics ceases to exist, this article presents a study of an attempt to re-embed nutrigenomics into nutrition science. It describes the opportunities and hurdles that researchers within two large Dutch research consortia (specifically the Top Institute Food and Nutrition (TIFN) and the Nutrigenomics Consortium (NC)) encountered when trying to cross the boundaries that were established over the last years. While some of the findings of this study are specific to the institutional and local contexts of the case study, they shed light on more general characteristics of the process to redefine the relationship between nutrigenomics and nutrition science. As such the findings may prove valuable for researchers facing shifting boundaries between nutrition science and nutrigenomics in particular, and integration in science in general (Parker \& Hampton, 2011).

\section{Case and method}

In 2004, the NC was founded as a part of the Netherlands Genomics Initiative to further molecular understanding of nutrition in general and of diet-related metabolic stress in particular. In 2009, its funding was not renewed. Instead, the future of the NC expertise, science and staff was expected to lie in TIFN, a Dutch long-term public-private partnership for interdisciplinary research in food and nutrition and the new knowledge hub for all dietetic matters. In addition to obvious financial considerations, there was a strong conceptual motivation behind the proposed organisational shift: TIFN management specifically identified synthesis between the two former organisations as a potential area of innovation and excellence. Combining traditional food research with new technologies and approaches could bring together the best of both worlds: nutrigenomics could reinforce dietary health claims by offering mechanistic insights in the workings of food. It could bring stratification based on response to interventions and active pathways within reach. At the same time, enhanced collaboration could pay academic dividend: applying new fundamental scientific insights to food research within TIFN would increase the chances of publication in highly cited journals. Despite these incentives, integration between 'traditional' and 'new' nutrition science remained limited. In 2010, after almost two years of attempts at integration, TIFN senior management realised that the challenges to renewed collaboration were not strictly scientific but included relevant social dimensions.

TIFN management therefore invited the CSG Centre for Society and the Life Sciences to advise on embedding of the NC within TIFN. This led to a collaborative project that aimed to identify the hurdles to collaboration and suggest ways to overcome them. Importantly, the project considered both the 'technical' challenges to integrating different knowledge areas and the 'social' challenges involved in integrating two research cultures. The research team consisted of a researcher with a background in biology and anthropology (SS) and two senior social researchers experienced in studying scientific collaboration and integration (BP) and responsible innovation and interdisciplinary approaches (DS). They met regularly with TIFN and CSG management and leading NC researchers.

We will first describe our methodological and theoretical approach to the sociological and organisational problems characteristic for the case. We will then highlight the four most salient hurdles and disclose the recommendations given to overcome these hurdles. We will also discuss how these findings may be relevant to other settings where nutrigenomic exceptionalism is ending.
The project consisted of three phases: an articulation phase, an empirical phase and an intervention phase. The articulation phase explored the current state of collaboration and integration of nutrigenomics in TIFN research via a literature survey and interviews with leading researchers from NC and TIFN. The empirical phase identified the most salient opportunities and barriers to integration in specific TIFN projects. The intervention phase discussed opportunities and barriers to integration in three workshops with TIFN-researchers and management. This article focuses on the results of the articulation and empirical phases, which provided input for recommendations (see Box 1) and the design of the interventions.

To identify the different hurdles to collaboration, we have used a qualitative research approach. Realising that the hurdles to collaboration and synthesis could be diverse, and that the hidden hurdles could well be more important than those prominently visible, SS immersed herself in the research practices in order to acquire a sufficient degree of formal and informal (tacit) knowledge about the practice. Immersion in the research practice entails a large amount of interaction with professionals and participation in the research practice (by joining in meetings, discussions, debates and through reading the relevant research literature) in order to build the required interactional expertise to recognise tacit elements in the research practice (Collins \& Evans, 2007). She held 30 semi-structured in-depth interviews with junior and senior scientists, technicians and administrators within TIFN and the NC. These interviews were recorded and transcribed ad verbatim. SS attended and participated in management meetings, work floor meetings, symposia, conferences and lectures and carefully documented each. Additionally, she conducted literature research including scientific publications, 'grey' literature, project proposals, mid-term evaluations and reports as well as relevant websites.

Data collection took place between April and October 2011. Analysis of the data delivered a range of hurdles to collaboration. The initial list was vetted in a process of dialogue with TIFN and NC researchers that continued into 2012.

\section{Results: hurdles to collaboration and synthesis}

The most salient hurdles opposing the use of nutrigenomics in TIFN research can be grouped into four main categories (1) complexity of and unfamiliarity with nutrigenomics; (2) unclear and unshared notions of relevance; (3) difficulties in organising proper data exchange; and most importantly, (4) the existence of two research cultures in knowledge institutes active in TIFN.

\subsection{Complexity and unfamiliarity}

What exactly nutrigenomics is, often proved unclear to nutrition scientists who had little experience in collaborating with nutrigenomicists. There are different definitions of nutrigenomics: some definitions restrict nutrigenomics to sequence-information, while others include transcriptomic, proteomic or metabolomic methodologies and data. In almost all cases, nutrigenomics is presented as a sophisticated approach to data collection and interpretation, but the relationship that exists between the high-tech data collection and analysis on the one hand, and phenotypical or physiological processes on the other, is often left implicit. Moreover, nutrigenomics is characterized in terminology derived from molecular biology, which does not directly resonate with nutrition scientists.

As a consequence of the variety of definitions and assumed approaches, respondents identified nutrigenomics as 'complicated', 'complex' and 'time-consuming'. They considered it far from easy to 
extract information from available micro-array data and subsequently connect this to existing knowledge about pathway activity, protein-protein interactions or physiology and/or phenotype. Each requires technical expertise (to perform the experiment), biological and nutritional expertise (to interpret this data and embed it in existing biological knowledge), as well as bioinformatic expertise (to establish validity and quantitative underpinning for the data) and most nutrition scientists do not have easy access to any of these three types of expertise.

One of the nutrition scientists who had some experience in collaborating with nutrigenomicists stated that "It has taken a tremendously long time before we started seeing the biological light at the end of the tunnel. This has to do with the fact that we had to train ourselves in seeing it. It is not something you can simply do" [Interview N52].

Collaborating with nutrigenomicists requires some expertise in nutrigenomics in order to grasp the complexity of the molecular data and its origins. Sociological literature states that for collaborative purposes the level of expertise does not have to be 'perfect', since it is meant to enable interaction rather than contribution (Collins \& Evans, 2007). Acquiring that expertise takes a lot of time and effort. As one PhD student remarked: "I think you should be very persistent [for this type of work], not to give up easily. In the beginning it took me at least one and a half year to understand, to interpret the data in a meaningful way. I had to be very patient and dedicated a lot of time to this study" [Interview L77].

\subsection{Relevance}

TIFN is a consortium of both public knowledge institutes and private companies. Almost all of the projects that take place in the consortium involve industrial partners. Since they bring in a relevant part of the funding, projects need to convince representatives from the R\&D departments of (usually) food companies that their goals and approaches are relevant scientifically, as well as relevant in terms of economic potential.

While most respondents recognised and appreciated the scientific contribution of nutrigenomics, they did not consider its contribution to physiological insights to be self-evident. Respondents from both food industry and academia argued that nutrigenomics is difficult to apply in a clinical setting and, as a result, is difficult to use as evidence for health claims (see also Biesalski et al. (2011)). Food industry's attitude towards nutrigenomics has been cautious, especially considering their interest in establishing support for health claims. One of the respondents, who is closely involved with the European Food Safety Authority (EFSA) doubted whether nutrigenomics can contribute to health claims at all: "I do not expect health claims to be made based on nutrigenomics. [ ... ] Physiology and clinically relevant endpoints are much more important" [Personal Communication].

The potential of nutrigenomics to support health claims could act as a catalyst for collaboration. But preferences for clinical methodologies and clinical endpoints over mechanistic evidence, as institutionalised in EFSA for example, continue to act as a hurdle for nutrition science-nutrigenomics collaborations (see also Hendrickx (2014)). The quote above testifies to this. While many researchers acknowledge that the goal of finding more mechanistic evidence has value in the long run, the focus on clinical endpoints associated with evidence-based medicine - directs their attention to more traditional types of research.

However, many food companies are pursuing short and longterm innovation strategies in parallel. Some innovations will require demonstration and evidence in a decade, while others are due tomorrow. The relevance of this temporal dimension is forwarded by one of the representatives of a large food company: "Many of us want to stay involved in this [nutrigenomics], at least on the sideline, just to see what comes out. It is not perceived as something we need to invest in to get products on the market in one, two or three years" [Interview 049].

The hierarchy of evidence is a characteristic of the current regulatory framework and as such shapes contemporary scientific practices and evidence production. Many of our respondents expressed hope and expectation at the temporary nature of this particular incarnation of the hierarchy of evidence, thus leaving the door open for alternative conceptualisations of evidence underpinning health claims, and thus alternative scenarios for the relevance of nutrigenomics in the future.

\subsection{Data exchange}

Collaboration requires sharing and exchange of (raw) data in order to produce additional value. This may generate different types of knowledge, complementary to one another but requiring a different set of expertise to create. The governance structure of TIFN however proved not to be conducive to this exchange.

In order to generate maximum potential for industrial relevance (and participation), TIFN has been set up as a modular governance structure. Industrial partners can participate (and thus invest) in the modules they care about, while not having to invest any resources in the modules they feel are of insufficient interest to them. To accommodate this modular structure, an intellectual property infrastructure has been set up which allows data to flow freely between partners inside any given module, but not beyond it. As a consequence, TIFN has been able to attract the interest of many additional food companies who previously were unable or unwilling to commit themselves financially to the institute's full research portfolio.

There is, however, a downside to this governance innovation. Especially for data-intensive fields of expertise, including nutrigenomics, the created silos act as a practical (and legal) hurdle. The added value of nutrigenomic approaches lies in their potential to identify and quantify connections in, across and between different data sets, inside and outside of the TIFN data infrastructure. A specific database infrastructure has been built for this purpose, called MadMax (Lin et al., 2011). In this MadMax database, data is collected from all TIFN modules. It is handled and stored centrally, yet because of the intellectual property infrastructure, datasets that exist in the same database cannot be compared, joined, merged, or used for meta-analysis. One of the database curators told us that intellectual property rights restrict researchers from access to other data sets. This makes exchange difficult, if not impossible. The curators observe the connections in the database yet are legally bound to keep them quiet. As a result, TIFN researchers consider it easier to collaborate with other nutrition scientists or nutrigenomicists outside of the organisation, and use their data, than to collaborate internally.

Participants in our study nearly all agreed that TIFN's future and relevance highly depended on the integration and accumulation of the various 'omics' databases the institute hosts. Paradoxically, TIFN's modular governance infrastructure increased the resources available for research but decreased its capacity for knowledge production through synthesis.

\subsection{Research cultures}

The most powerful, yet presumably most hidden hurdle to increased collaboration between nutrition scientists and nutrigenomicists inside and beyond TIFN is the existence of two different conceptualisations, or visions, of nutrigenomics in relation to 
nutrition science. On one view, nutrigenomics is seen as a toolbox: nutrigenomics researchers can provide assistance to nutrition researchers through the use of existing techniques and methods such as micro-arrays. The second view positions nutrigenomics as an autonomous discipline, an entirely new research paradigm with its own questions and hypotheses. These are the extreme positions, and while they are not always held absolutely, they help to explain why collaboration proved difficult: the view of nutrigenomics as a toolbox holds very little promise for nutrigenomicists. While such a supportive role may be useful to TIFN research, it does not offer opportunities in terms of advancing the research field, nor allows researchers to build credibility for themselves as experts. As one of the nutrigenomicists argued: "I have no problems with providing a service once in a while, but the [nutrigenomics centre] is not just a service-provider. We want to be involved scientifically as well" [Workshop 2]. Conversely, it is very difficult to imagine for nutrition researchers the relevance of nutrigenomics if it is presented as an autonomous discipline, pursuing only the research interests within the new paradigm.

Depending on their vision of nutrigenomics, researchers thus turned out to have radically different expectations of the roles they and others ought to play in any collaboration, the power distribution that accompanies such roles, and the character and content of the science being performed in these collaborations. These diverging views suggest the existence of two distinct research cultures, separated by - amongst other things - their conceptualisation of the status of nutrigenomic inquiry inside the participating knowledge institutes of TIFN. The active differentiation between objects of research, patterns of explanation and methods to move from object to explanation has been described as 'styles' or cultures, historically (Crombie, 1994; Knorr-Cetina, 1999; Pickstone, 2000), philosophically (Hacking, 1992) and sociologically (Fleck, 1980 [1935]; Fujimura \& Chou, 1994; Gieryn, 1999). Such epistemic boundaries have been discussed before with respect to nutrition science (Penders, Vos, \& Horstman, 2009) and bioinformatics (Lewis \& Bartlett, 2013). 'Traditional' nutrition science and 'new' nutrition science (nutrigenomics) are separated by such a boundary, distinguishing the molecular and genetic from the physiological and toxicological (the object) and the mathematical and statistical from the experimental and observational (explanation), as well as indicated by different department, journals, and even a different vocabulary for assessing the truth and credibility of knowledge (Penders, Horstman, \& Vos, 2008). Through interactions, discussions, engagements and debate, this boundary is both actively maintained (reinforcing difference, lowering proximity) and actively transgressed (downplaying difference, reinforcing proximity).

What literature on research cultures teaches us is that each encounter between different research cultures is accompanied by its own definitions of its boundaries and is made manifest through materials and arguments unique to that culture. The two nutritional research cultures, 'new' and 'traditional', study different things differently, they publish elsewhere using a different vocabulary and hold different expectations of the role of the 'other'.

While traditional nutrition scientists measure metabolites, nutrigenomicists measure gene expression (Observation Y06, 2011); while nutrition scientists favour pharmacologically validated biomarkers, nutrigenomicists aim to construct new ones (Observations C67, 2011) and while nutrition scientists judge according to clinical relevance, nutrigenomicists work with statistical and model-based relevance (Interview K86). These different elements in the research culture translate to the use of different tools and equipments, a different jargon and different goals for research, discriminating between epidemiological research and 'mechanistic' research - or, in our terminology, between traditional nutrition science research culture and nutrigenomic research culture. As one of the nutrigenomicists explains:

Epidemiological research offers correlation with huge numbers of confounders. That is often a starting point for more research. We have brought mechanisms to food science. We can follow precisely what happens in the gut, liver and fatty tissues and reconstruct what the body really does with food (Interview W38).

Nutrigenomicists argue in interviews that they consider traditional nutrition scientists to be excellent scientists, limited only by the 'traditional' research culture and the methodological and analytical choices that accompany it. A limit, they can remedy. Nutrition scientists, on the other hand, see nutrigenomics as an approach with an astonishing resolution, yet without any current clinical relevance - which they can offer. These research cultures and the assumptions of one about the other, shape the envisioned role for nutrigenomics in both the present and the future.

\section{Conclusion and discussion}

In the case of our collaborative project, enhanced understanding of the hurdles to collaboration also pointed towards a solution. During the final stage of our collaborative project, we identified recommendations (see Box 1) to encourage integration of nutrigenomics in TIFN research. The recommendations identified opportunities for collaboration that allowed nutrigenomicists to advance their research while being relevant to ongoing TIFNresearch projects, combining the vision of nutrigenomics as a toolbox and as an autonomous discipline. Interestingly, researchers' enhanced awareness of these competing visions was a prerequisite for collaboration: once researchers from the two cultures started looking for new activities that were both relevant to TIFN-projects and interesting to nutrigenomics, common ground was readily identified. Indeed, integration matters: both NC and TIFN researchers agreed that -omics technologies will be vital to nutrition science, as they can elucidate the mechanistic causes of specific responses to nutrition that correlational research cannot reveal. The effective integration of nutrigenomics techniques in nutrition research would allow TIFN to play a leading role in the field of nutrition science.

This case suggests that harnessing the potential of nutrigenomics within nutrition science is not merely a technological or scientific challenge, but vitally depends on the fulfilment of social criteria: familiarity with the possibilities of nutrigenomics and its research agenda, enhanced interactions between researchers, mutual recognition for different forms of expertise, and effective support mechanisms.

Extrapolating from the findings of our study, what might be expected of nutrigenomics in the context of nutrition science? Two scenarios present themselves. On the one hand, nutrition science's research culture could re-engulf the nutrigenomic research culture, assimilating what is useful and valuable into itself. One the other hand, the nutrigenomic research culture may break free from more traditional nutritional science and craft a disciplinary status for itself. On the long run, developments like the latter may give rise to new (sub)disciplines and areas of specialisation (Penders et al., 2009; Schoenberger, 2011). The effort and resources invested in advancing nutrigenomics has provided it with its own developmental trajectory. The call for re-integration in The Netherlands as discussed in this paper suggests that the legitimation for it having its own trajectory is now questioned. The role that nutrigenomics plays within the greater area of nutrition science over the last ten years has been characterised by contrasting and perhaps 
paradoxical dynamics of divergence and convergence. This situation is likely to continue and the oscillatory movements will continue to shape the field, and the collaborations it contains.

The status of nutrigenomics in nutrition science has, in addition to the practical dimension alluded to above, also a political dimension. Political, because it deals with the power to establish any given nutritional future. Nutrigenomics represents, to a certain extent, a different agenda for the future of nutritional innovation. It dreams of personalisation and large-scale stratification when it comes to health effects and health claims, whereas the dominant approaches in nutrition are still geared towards more uniformity. In the context of increasing public-private governance in nutrition science and innovation, such different foci also translate into different investment strategies: large, high-risk and uncertain

\section{Box 1}

Recommendations

Recommendations were meant specifically to address the hurdles and strengthen collaborations in ways that safeguarded both the relevance of nutrigenomics for TIFNprojects and autonomy of the NC. The main recommendations were:

1) Improving information exchange on the possibilities of nutrigenomics for TIFN research, e.g. by an introductory course on data-analysis and -interpretation could greatly improve TINF-researchers' understanding of the possibilities of nutrigenomics, and simultaneously enhance the quality of nutrigenomics data and -analysis; workshops organised during the intervention phase provided a proof-of-principle, resulting in increased interest and interaction.

2) Pointing to the potential industrial relevance of nutrigenomics through best practices and pilot projects. Interviews and workshops identified several promising uses of nutrigenomics techniques in TIFN-research, but most researchers were as yet unfamiliar with them. Initiating and communicating further pilot projects could further enhance the visibility of nutrigenomics, supporting TIFN research projects while advancing its own research agenda,

3) Review of experimental design of TIFN projects by NC researchers. Robust experimental design is crucial to the reproducibility of nutrigenomics research. Involving NC researchers early in research project design could help in improving the usability and comparability of research data (for instance by standardising animal diet).

4) More explicit descriptions of nutrigenomics activities within project proposals and earmarked allocation of resources for project funding and staff. We recommend that nutrigenomics researchers offer support in all stages of the research, from experimental design up to final publication. This, however, requires allocation of appropriate resources.

5) Improved data sharing regimes. The added value of nutrigenomics resides in the analyses of datasets deriving from a range of research projects. Current intellectual property regimes resist sharing data, posing a barrier to optimal use of research results. Researchers agreed that the establishment of superordinate databases were vital to unlock nutrigenomics' full potential. investments with the promise of large effects and large returns on the long run, versus quick and more certain results on the short run. Thus, the status of a body of knowledge translates into a political arena of power, influence and investment shaping our nutritional future.

Scientific collaboration is well-studied sociologically (Parker, Vermeulen, \& Penders, 2010; Shrum, Genuth, \& Chompalov, 2007), showing that similar epistemological and political boundaries traverse the map of science, and form both a fundamental characteristic of scientific activity, and a fundamental motivator to collaborate (Hackett, 2005). Successful collaboration is about overcoming the hurdles that these boundaries pose.

The perceived complexity of an approach or field - flowing from unfamiliarity with it - is a hurdle that is the easiest to remedy. Well-trodden paths include training and exposure, in which the first is a formalised encounter with something new, while the latter is often less formal, but more intense. The difficulties in perceived relevance tie into familiarity with a novel approach: if one cannot oversee a body of expertise, it is difficult to assess its potential and relevance. However, more knowledge is not by default the route to appreciation. We know from the public understanding of science that more knowledge does not automatically translate into more trust, or a more positive attitude (Wynne, 1992, 1995). This flows from the connection of the perception of relevance to the research culture from which one views that relevance. Governance structures further exacerbate the limits to collaboration, even materially. The specific 'data silos' we diagnosed at TIFN are case-specific, but given the motivations that led to them, we may expect an increasing occurrence of governance structures that limit collaboration in some form or another.

Thus, social analysis of the criteria for embedding nutrigenomics in TIFN research not only elucidates the motivations for collaboration in this specific organisation and context - it also hints at the general dynamics of collaboration in science and the ways in which competing visions of the future shape the establishment of new nutritional futures.

\section{Acknowledgements}

This study was supported by a valorisation grant from the Top Institute Food and Nutrition (TIFN) and the CSG Centre for Society and the Life Sciences. We thank all TIFN, NC and CSG staff who generously participated in our research.

\section{References}

Biesalski, H. K., Aggett, P. J., Anton, R., Bernstein, P. S., Blumberg, J., Heaney, R. P., et al. (2011). 26th Hohenheim consensus conference, September 11, 2010 scientific substantiation of health claims: evidence-based nutrition. Nutrition, 27, $\mathrm{S} 1-\mathrm{S} 20$.

Collins, H. M., \& Evans, R. (2007). Rethinking expertise. Chicago \& London: The University of Chicago Press.

Crombie, A. (1994). Styles of scientific thinking in the European tradition. In The history of argument and explanation in the mathematical and biomedical sciences and arts (Vol. 3). London: Duckworth.

Fleck, L. (1980 [1935]). Entstehung und Entwicklung einer Wissenschaftlichen Tatsache. Einführung in die Lehre vom Denkstil und Denkkollektiv. Frankfurt am Main: Suhrkamp.

Fujimura, J. H., \& Chou, D. Y. (1994). Dissident in science: styles of scientific practice and controversy over the cause of aids. Social Science in Medicine, 38, 1017-1036.

Gieryn, T. F. (1999). Cultural boundaries of science. Credibility on the line. Chicago \& London: University of Chicago Press.

Hackett, E. J. (2005). Introduction to the special guest-edited issue on scientific collaboration. Social Studies of Science, 35(5), 667-672.

Hacking, I. (1992). 'Style' for historians and philosophers. Studies in History and Philosophy of Science, 23, 1-20.

Hendrickx, K. (2014). Bodies of evidence. An anthropology of the health claim. Liège (B): Université de Liège.

Knorr-Cetina, K. (1999). Epistemic cultures: How the sciences make knowledge. 
Cambridge MA \& London: Harvard University Press.

Lewis, J., \& Bartlett, A. (2013). Inscribing a discipline: tensions in the field of bioinformatics. New Genetics and Society, 32, 243-263.

Lin, K., Kools, H., de Groot, P. J., Gavai, A. K., Basnet, R. K., Cheng, F., et al. (2011). MADMAX - management and analysis database for multiple omics experiments. Journal of Integrative Bioinformatics, 8, 160.

Müller, M., \& Kersten, S. (2003). Nutrigenomics: goals and strategies. Nature Reviews Genetics, 4, 315-322.

Parker, J. N., \& Hampton, S. E. (2011). Collaboration and productivity in scientific synthesis. BioScience, 61, 900-910.

Parker, J. N., Vermeulen, N., \& Penders, B. (2010). Collaboration in the new life sciences. Farnham (UK): Ashgate.

Penders, B., \& Goven, J. (2010). Nutrigenomics and the stewardship of scientific promises. Biotechnology Journal, 5, 909-912.

Penders, B., Horstman, K., \& Vos, R. (2008). Walking the line between lab and computation: the 'moist' zone. Bioscience, 58, 747-755.
Penders, B., Vos, R., \& Horstman, K. (2009). A question of style: method, integrity and the meaning of proper science. Endeavour, 33, 93-98.

Pickstone, J. V. (2000). Ways of knowing. A new history of science, technology and medicine. Manchester: Manchester University Press.

Schoenberger, E. (2011). Interdisciplinarity and social power. Progress in Human Geography, 25, 365-382.

Shrum, W., Genuth, J., \& Chompalov, I. (2007). Structures of scientific collaboration. Cambridge, MA: MIT Press.

Webster, A. (2007). Crossing boundaries social science in the policy room. Science, Technology \& Human Values, 32, 458-478.

Wynne, B. (1992). Misunderstood misunderstandings: social identities and the public uptake of science. Public Understanding of Science, 1, 281-304.

Wynne, B. (1995). Public understanding of science. In S. Jasanoff, G. E. Markle, J. C. Petersen, \& T. Pinch (Eds.), Handbook of science and technology studies (pp. 361-389). London: Sage. 